\title{
Article \\ An Investment Decision-Making Approach for Power Grid Projects: A Multi-Objective Optimization Model
}

\author{
Lei Gao ${ }^{1}$, Zhen-Yu Zhao ${ }^{2}$ and Cui Li ${ }^{1, *}$
}

1 School of Economics and Management, Institute of Disaster Prevention, Sanhe 065201, China; gaolei@cidp.edu.cn

2 Beijing Key Laboratory of New Energy and Low-Carbon Development, School of Economics and Management, North China Electric Power University, Beijing 102206, China; zhzhy@ncepu.edu.cn

* Correspondence: licui@cidp.edu.cn

check for updates

Citation: Gao, L.; Zhao, Z.-Y.; Li, C. An Investment Decision-Making Approach for Power Grid Projects: A Multi-Objective Optimization Model. Energies 2022, 15, 1112. https:// doi.org/10.3390/en15031112

Academic Editor: Dimitrios

Katsaprakakis

Received: 4 January 2022

Accepted: 31 January 2022

Published: 2 February 2022

Publisher's Note: MDPI stays neutral with regard to jurisdictional claims in published maps and institutional affiliations.

Copyright: (c) 2022 by the authors. Licensee MDPI, Basel, Switzerland. This article is an open access article distributed under the terms and conditions of the Creative Commons Attribution (CC BY) license (https:// creativecommons.org/licenses/by/ $4.0 /)$.

\begin{abstract}
With the reform of the power system in China, investments in power grid projects across the whole power system are increasing. However, there are various objectives to achieve in the investment decision processes of power grid projects, so the rational investments of a grid project can be seen as a multi-objective optimization problem. Meanwhile, these issues have rarely been studied at home and abroad, and this paper will fill this gap. As a result, this study critically analyzed the application of a multi-objective optimization model to power grid investment. Firstly, the objective factors of grid investments were explored, which were quantified through quantitative methods. Secondly, based on the characteristics of power grid investment, a multi-objective optimization model was established, and the assumptions and constraints of the model were presented. Finally, NSGA-II was used for solving the multi-objective optimization model. The results show that: (1) Multiobjective optimization models are suitable for the study of and deriving solutions for power grid investment by establishing suitable objective functions, assumptions and constraints, (2) According to the conventional steps of NSGA-II, suitable steps can be established to search for an optimal solution to the objective set of a power grid investment and (3) Due to the different concerns of different project scenarios, Pareto frontier solutions can be selected as the practical references of power grid projects. Therefore, the solution set makes the implementation scheme more flexible.
\end{abstract}

Keywords: power grid projects; investment decision-making; multi-objective optimization models; NSGA-II

\section{Introduction}

With the further escalation of China's new round of power system reform, the effect of "controlling the middle" has become significant. Meanwhile, this reform has changed the supervision mode of power grid enterprises, resulting in the transformation of the power grid construction mode, operation mode, investment proportion and profit mode of power grid enterprises. In November 2019, the State Grid Corporation of China and China Southern Power Grid Corporation promulgated "the notice on further strict control of grid investment (No. 826 document)" and "measures for optimizing investment and cost control (2019 version)" [1,2], which made it clear that the input-output mechanism should be market-oriented throughout the whole process of power grid projects. Furthermore, in order to achieve "peak carbon emissions" by 2030 and "carbon neutrality" by 2060, resource deployment should be concentrated on the key links and key areas of power projects in China. Therefore, the precise investment pattern of power grid construction projects needs to be established.

In the last decade, there has been an increasing number of studies concerning grid construction investment. For example, Zhao et al. [3] conducted a factor analysis of investment in a $35 \mathrm{kV}$ transmission line project, and the impact and extent of each factor were determined. Similarly, Zhao et al. [4] built a comprehensive evaluation model for 
grid construction project investment based on the improved AHP. As this research has intensified, various models and indicators have been applied to investment studies of power grid projects. For instance, He et al. [5] used system dynamics to study the relationship between grid investment decisions and key indicators such as electricity increases, profit growth and gearing. Schachter et al. [6] proposed a real option method to assess investment in smart grid development. Zhu. [7] proposed a quantitative model of investment decision support for power grid enterprises. Furthermore, Ma et al. [8] established a power grid project investment evaluation index system based on three types of indices: technology, benefit and project maturity. Chang et al. [9] proposed an investment optimization decisionmaking method for multiple power grid construction projects under a certain investment scale, and they also developed a holographic risk assessment index system.

In addition, multi-objective optimization models and algorithms are used in many areas of the power system. For example, the following have been recorded in the literature: maintenance schemes for nuclear power plants [10], design optimization of geothermal power generation and solid waste power plants [11,12], multi-objective optimization of water energy emissions from coal-fired power plants [13], optimization of hybrid renewable energy power systems [14], optimal planning of power systems with wind farms [15,16], optimal integrating renewable energy sources into power grid $[17,18]$ and multi-objective combined heat and power units [19]. Meanwhile, there are many types of multi-objective optimization algorithms, and they can provide valuable reference for investment decision making for power grid construction projects, with examples of these algorithms including the simulated annealing-chaotic search [20], multi-objective hybrid grey wolf optimizer [21], multi-objective dragonfly [22] and multi-objective enhanced immune algorithms [23]. Furthermore, as the common multi-objective optimization algorithms, both particle swarm optimization (PSO) and genetic algorithms (GA) have the property of searching for the best solution from a large number of solutions. For instance, PSO is applied to perform validation calculations on optimization schemes [24], conduct the multi-objective optimization of equipment capacity and operation [25] and solve the extended travelling salesman problem [26]. GA is applied to assess system reliability [27], estimate energy plant size [28] and determine optimal operating parameters [29].

However, genetic algorithms are more widely used in the multi-objective optimization of the power system compared with PSO and the above algorithms. Due to the evolutionary characteristics, genetic algorithms do not need the internal properties of the problem in the process of searching for the optimal solution set. As a result, they can deal with any form of objectives or constraints, whether they are linear, nonlinear, discrete or continuous. In power system applications, Gentils et al. [30] investigated the problem of optimizing a support structure to reduce the cost of offshore wind turbine groups. A genetic algorithm (GA) was used to develop an optimization model for the support structure. Ershadi et al. [31] used a genetic algorithm to simulate and optimize a combined cooling, heating and power system. On this basis, the benefits of selling electricity to the grid under different scenarios were calculated. Bogdan et al. [32] proposed the distribution system reconfigurations that need to consider various criteria for distribution grid network operational performance optimization. A genetic algorithm was used to solve the problem, and the accuracy and efficiency of the algorithm was demonstrated by comparison on a test system. Furthermore, with the improvement of searching accuracy, non-dominated sorting genetic algorithm (NSGA-II) with elite strategy was proposed on the basis of GA. The NSGA-II also has various applications in the field of power system. Javad et al. [33] studied the generation capacity and generation revenue of storage systems for solar power plants. A dynamic planning algorithm was established through comparisons with NSGA-II. Xu et al. [34] used a modified NSGA-II based on reinforcement learning to determine a set of Pareto solutions. The objectives considered are to minimize the levelized cost of energy (LCOE), the loss of power supply possibility (LPSP) and the power abandonment rate (PAR). Zhang et al. [35] proposed the NSGA-II to analyze decision variables on the number of wind turbines, PV modules and battery banks with the total system cost (TSC) 
and the loss of power supply probability (LPSP) as the objective functions. Wu et al. [36] used NSGA-II to obtain the Pareto optimization curve, and explore trade-offs between economic and environmental goals.

As an important type of infrastructure, the safe and stable operation of power grids is closely related to national living. The characteristics of power grid construction include high technology content, huge investment, long income cycles, and many participants. Therefore, there are many problems in the implementation processes of power grid construction projects, and different factors therefore must be considered comprehensively. This can be regarded as multi-agent, multi-stage and multi-objective decision-making research. In addition, these factors have strong correlations between them, such as that between construction time sequence allocation and resource balanced allocation, which directly affects risk aversion and power supply stability. Thus, the balancing of various factors can be summarized as decision making for investment scheme selection. Similarly, it can be seen as the multi-objective optimization problem in the construction of power grid projects.

In summary, our study was structured around three main objectives: (1) Selecting objective functions for grid investment projects and establishing a multi-objective optimization model of investment decisions; (2) Determining the assumptions under which our model was built, and how it was solved by using NSGA-II and (3) Selecting a reasonable set of investment decision solutions for different characteristics of grid projects.

The remainder of this paper is constructed as follows. In Section 2, the multi-objective optimization model of grid investment projects is described. Moreover, the NSGA-II algorithm and computational logic are presented. In Section 3, the description of a case study and a computational solution are presented. Furthermore, the applicability of NSGA-II is discussed by comparing three types of algorithms. In Section 4, the selection of a multi-objective optimal solution set for different scenarios is proposed. In Section 5 , concluding remarks and future research directions are provided.

\section{Materials and Methods}

Multi-objective optimization is a common problem in real life and involves situations when a problem that has to be optimized has multiple objective functions, and the objective function has the same priority, or the priority is matched according to the objective weight. Therefore, we need to make the objective function as optimal as possible at the same time within a clear range. It is also one of the problems that needs to be studied in power planning, construction and load distribution.

\subsection{Mathematical Description of Multi-Objective Optimization}

The multi-objective optimization problem is generally composed of constraint equations or inequalities related to multiple objective functions. In general, the variable of decision space is seen as n-dimensional. From a mathematical point of view, the formula of the multi-objective optimization problem can be expressed as:

$$
\left\{\begin{array}{c}
\operatorname{minf}_{1}\left(\mathrm{x}_{1}, \mathrm{x}_{2}, \ldots, \mathrm{x}_{\mathrm{n}}\right) \\
\ldots \ldots \\
\operatorname{minf}_{\mathrm{h}}\left(\mathrm{x}_{1}, \mathrm{x}_{2}, \ldots, \mathrm{x}_{\mathrm{n}}\right) \\
\operatorname{maxf}_{\mathrm{h}+1}\left(\mathrm{x}_{1}, \mathrm{x}_{2}, \ldots, \mathrm{x}_{\mathrm{n}}\right) \\
\ldots \ldots \\
\operatorname{maxf}_{\mathrm{k}}\left(\mathrm{x}_{1}, \mathrm{x}_{2}, \ldots, \mathrm{x}_{\mathrm{n}}\right) \\
\text { s.t. } \mathrm{e}_{\mathrm{i}}(\mathrm{x}) \geq 0, i=1,2, \ldots, \mathrm{r} \\
\mathrm{g}_{\mathrm{j}}(\mathrm{x})=0, \mathrm{j}=1,2, \ldots, \mathrm{s}
\end{array}\right.
$$

where $f_{i}(x)$ represents the objective function, and the value range is $\{i=1,2, \ldots, k\}$. The constraint functions are $e_{i}(x)$ and $g_{j}(x)$, the design variable set is $x$, and the value range of $x$ is $\left\{x_{1}, x_{2}, \ldots, x_{n}\right\}^{k}$. The objective functions' number for the multi-objective optimization problem is $\mathrm{k}(\mathrm{k} \geq 2)$, including $\mathrm{h}$ minimum objective functions and $\mathrm{k}-\mathrm{h}$ maximum objective 
functions. In addition, the number of constraint functions is $r+s$, the number of inequality constraints is $r$, and the number of equality constraints is $s, r, s \geq 0$. Therefore, the above can be simplified into a multi-objective optimization model as:

$$
\left\{\begin{array}{c}
\min \text { or } \max F(X)=\left[f_{1}(x), f_{2}(x), \ldots, f_{n}(x)\right] \\
\text { s.t. } e_{i}(x) \geq 0, i=1,2, \ldots, r \\
g_{j}(x)=0, j=1,2, \ldots, s
\end{array}\right.
$$

Therefore, the three factors of the multi-objective optimization problem are the following: the objective system, alternatives and decision criterion factors. The meanings of the three factors are as follows.

(1) The objective system is the set of objectives that the decision maker wants to achieve. It can usually be expressed in the form of an objective function. For example, in the above optimization model, the objective system is $f_{1}(x), f_{2}(x), \ldots, f_{n}(x)$. The decision maker hopes these functions can reach the optimal solution.

(2) The alternatives are the corresponding variables $x_{1}, x_{2}, \ldots, x_{n}$. In the practical application of a given project, the values of different variables are the variable contents specified according to the optimization requirements, which means the emergence of different optimization schemes. The alternatives can be expressed as $x=\left\{x_{1}, x_{2}, \ldots, x_{n}\right\}^{k}$, which can also be called a design variable set.

(3) The decision criterion is the constraint condition of variables. In the above mathematical expression, the equations and non-equations in the constraint functions are used to limit the range of variables. A group of variables that meets the constraint condition is a group or a feasible solution, and all variables that meet the constraint condition constitute a feasible solution set or a feasible region.

For grid construction, five types of objectives were used in this study: construction cycle, site selection investment, construction investment, operation investment and resource deployment objectives [37]. The construction cycle is the total time taken to complete the construction task. Site selection investment is the comprehensive cost content of the project site selection. Next, the investment in construction and operation covers the full life cycle of the grid. Finally, resource deployment is the key element content that ensures efficient resource allocation and power supply stability in the construction task.

\subsection{Multi-Objective Quantitative Calculation of Power Grid Projects}

\subsubsection{First Objective Function: Minimizing the Construction Cycle}

The efficient completion of construction tasks in the power grid construction cycle is expressed in the form of project schedule optimization. This cycle extends from the project's inception to its commissioning. In addition, various uncertainties and risk situations are included in the scope of the study on a probabilistic basis, such as the schedule risk, safety risk, quality risk and environmental risk. The objective function of the construction period can be expressed as the following:

$$
\min \mathrm{f}_{1}(\mathrm{x})=\mathrm{T}_{\mathrm{t}}=\sum_{\mathrm{t}=1}^{\mathrm{T}}\left(\mathrm{Su}_{\mathrm{t}}+\mathrm{De}_{\mathrm{t}} \mathrm{Od}_{\mathrm{t}}+\mathrm{Ex}_{\mathrm{t}}\right)
$$

where $\mathrm{T}_{\mathrm{t}}$ is the total construction period, $\mathrm{Su}_{\mathrm{t}}$ denotes the duration of each sub-project, and $D e_{t}$ represents the delays caused by the quality or safety conditions of the sub-projects, with all of these expressed in days. $\mathrm{Od}_{t}$ is the probability of quality or safety accidents in the sub-projects, expressed in \%, and $E x_{t}$ denotes delays due to external factors, expressed in days. External factors can be weather, policy, standards, etc.

\subsubsection{Second Objective Function: Minimizing Site Selection Investment}

Site selection for power grid construction mainly involves site selection and reasonable investment in substations and cable ducts, which are the key deciding factors of a power grid's orientation and access distance, and can be expressed quantitatively as compensa- 
tion costs related to land acquisition and demolition. As each province in China has its own compensation management method for land acquisition for construction, this paper integrates the "Land Management Law of the People's Republic of China" and "Beijing Construction Land Acquisition Compensation and Resettlement Measures" [38,39]. Routinely, investment in land acquisition and demolition mainly includes land compensation fees, resettlement subsidy fees, compensation fees for ground materials, preliminary fees, financial fees, unforeseeable fees, etc., which should be selected and calculated according to the project characteristics. The objective function of site selection investment can be expressed as the following:

$$
\min \mathrm{f}_{2}(\mathrm{x})=\mathrm{C}_{\text {site }}=\sum_{\mathrm{I}=1}^{\mathrm{N}}\left(\mathrm{La}_{\mathrm{I}}+\mathrm{Se}_{\mathrm{I}}+\mathrm{Gr}_{\mathrm{I}}+\mathrm{Pr}_{\mathrm{I}}+\mathrm{Fi}_{\mathrm{I}}+\mathrm{Un}_{\mathrm{I}}\right)
$$

where $C_{\text {site }}$ is the site selection cost, $¥ 10,000$. La $a_{\text {I }}$ denotes the land compensation cost for project I, $¥ 10,000$; this covers compensation for agricultural land, compensation for construction land and compensation for unclaimed land. $\mathrm{Se}_{\mathrm{I}}$ represents the resettlement subsidy for project I, $¥ 10,000$; it covers the resettlement subsidy for the agricultural population, relocation subsidy, temporary resettlement subsidy, loss of production and business stoppage, etc. $\mathrm{Gr}_{I}$ denotes the above-ground compensation for project I, $¥ 10,000$, including compensation for buildings, seedlings, scattered trees, etc. $\operatorname{Pr}_{\mathrm{I}}$ is the pre-project cost for project $\mathrm{I}$, $¥ 10,000$, including the cost of the feasibility study and the implementation plan for land development, the general site survey and staking cost, environmental impact assessment, geological hazard assessment, etc. $\mathrm{Fi}_{\mathrm{I}}$ represents the financial charges of project I, $¥ 10,000$; this is the cost of using funds, such as interest on bank loans. $\mathrm{Un}_{\mathrm{I}}$ denotes the unforeseen costs of project I, $¥ 10,000$, which involves the costs of dealing with uncertain risk factors, and is generally calculated at $5 \%$ of the site selection investment.

\subsubsection{Third Objective Function: Minimizing Construction Investment}

According to the Budgeting and calculation standards for power grid construction and the China electrical engineering cost information network $[40,41]$, construction investment can be quantified as the foundation treatment cost, equipment acquisition cost, building construction cost, other construction costs and the reserve cost. The objective function of construction investment can be expressed as the following:

$$
\min \mathrm{f}_{3}(\mathrm{x})=\mathrm{C}_{\mathrm{con}}=\sum_{\mathrm{I}=1}^{\mathrm{N}}\left(\mathrm{Fo}_{\mathrm{I}}+\mathrm{Eq}_{\mathrm{I}}+\mathrm{Bo}_{\mathrm{I}}+\mathrm{Ot}_{\mathrm{I}}+\mathrm{Re}_{\mathrm{I}}\right)
$$

where $C_{\text {con }}$ is the construction cost, $¥ 10,000$. Fo I $_{\text {I }}$ represents the foundation treatment cost of the project I, $¥ 10,000$, which routinely includes the costs of geological surveys, foundation design and foundation construction. $\mathrm{Eq}_{\mathrm{I}}$ denotes the equipment costs of project I, $¥ 10,000$, including the original cost of the equipment, freight and miscellaneous charges, transport insurance and storage costs. $\mathrm{Bo}_{\mathrm{I}}$ is the main body cost of project $\mathrm{I}, ¥ 10,000$; this covers the costs of the main structure of the substation, cable overhead laying, cable ducting or direct burial laying, etc. $\mathrm{Ot}_{\mathrm{I}}$ denotes the other costs for the engineering construction of project $\mathrm{I}$, $¥ 10,000$, which is charged according to the project characteristics. It generally includes the preparation of feasibility study reports, and survey, design, supervision, bidding agent, project management, construction drawing review, as-built drawing preparation, and environmental impact assessment costs, etc. $\mathrm{Re}_{\mathrm{I}}$ represents the costs of dealing with the uncertain risk factors of project I, $¥ 10,000$, and is generally calculated at $5 \%$ of the construction investment.

\subsubsection{Fourth Objective Function: Minimizing Operation Investment}

Similarly, according to the Budgeting and calculation standards for power grid construction and the China electrical engineering cost information network $[40,41]$, the operation cost can be quantified as material and equipment renewal costs, repair and maintenance 
costs, salary and welfare costs and other operation costs. The objective function of operation investment can be expressed as the following:

$$
\min \mathrm{f}_{4}(\mathrm{x})=\mathrm{C}_{\text {ope }}=\sum_{\mathrm{I}=1}^{\mathrm{N}} \sum_{\mathrm{j}=1}^{\mathrm{J}}\left(\mathrm{Em}_{\mathrm{I}, \mathrm{j}}+\mathrm{Ma}_{\mathrm{I}, \mathrm{j}}+\mathrm{Wa}_{\mathrm{I}, \mathrm{j}}+\mathrm{Op}_{\mathrm{I}, \mathrm{j}}\right)
$$

where $C_{\text {ope }}$ is the operation cost, $¥ 10,000$. Em $\mathrm{E}_{\mathrm{I}, \mathrm{j}}$ denotes the materials and equipment renewal costs during the operation of project $I$ in year $j, ¥ 10,000$. $\mathrm{Ma}_{\mathrm{I}, \mathrm{j}}$ represents the repair and maintenance costs during the operation of project $I$ in year $j, ¥ 10,000$. $W a_{I, j}$ is the salary and welfare costs for all personnel involved in the operation of project I in year $\mathrm{j}, ¥ 10,000$. Op $\mathrm{p}_{\mathrm{I}, \mathrm{j}}$ denotes the other related operating costs during the operation of project I in year $j$, $¥ 10,000$.

\subsubsection{Fifth Objective Function: Minimizing Resource Deployment Imbalance}

Resource allocation includes two levels of objectives. The first level is the optimal allocation of resources to ensure the normal implementation of the project, where labor, material and machinery costs are taken out of the construction costs and studied separately. The second level is balanced resource allocation, where the objective is to avoid power outages caused by centralized construction, to reduce the impact of the construction process on demand-side loads and to ensure the continued stability of the power system. Therefore, this objective is represented by a model of the balanced allocation of labor, materials and machinery. In addition, in the construction process, workdays are used as the unit of calculation for labor costs. Similarly, machinery hours are used as the unit of calculation for machinery costs, and materials are calculated according to different types in accordance with the material consumption and unit prices. For the convenience of this study, labor and machinery costs are not differentiated between labor and machinery types. The objective function of the first level objective can be expressed as the following:

$$
\begin{gathered}
\operatorname{Min}_{5}(\mathrm{x})=\mathrm{R}_{\text {total }}= \\
\sum_{\mathrm{I}=1}^{\mathrm{N}} \sum_{\mathrm{k}=1}^{\mathrm{K}} \mathrm{Md}_{\mathrm{I}, \mathrm{k}} \cdot \mathrm{Wu}_{\mathrm{I}, \mathrm{k}}+\sum_{\mathrm{I}=1}^{\mathrm{N}} \sum_{\mathrm{k}=1}^{\mathrm{K}} \mathrm{Mc}_{\mathrm{I}, \mathrm{k}} \cdot \mathrm{Mu}_{\mathrm{I}, \mathrm{k}}+\sum_{\mathrm{I}=1}^{\mathrm{N}} \sum_{\mathrm{k}=1}^{\mathrm{K}} \sum_{\mathrm{l}=1}^{\mathrm{L}} \mathrm{Mt}_{\mathrm{I}, \mathrm{k}, \mathrm{l}} \cdot \mathrm{Mp}_{\mathrm{I}, \mathrm{k}, \mathrm{I}}
\end{gathered}
$$

where $R_{\text {total }}$ is the total redeployment of resources. $\mathrm{Md}_{\mathrm{I}, \mathrm{k}}$ denotes the consumption of workdays of the sub-project $\mathrm{k}$ in the project $\mathrm{I}$, expressed in workdays. $\mathrm{Wu}_{\mathrm{I}, \mathrm{k}}$ represents the daily wages for the sub-project $\mathrm{k}$ of the project I, expressed in $\mathrm{CNY}$. $\mathrm{Mc}_{\mathrm{I}, \mathrm{k}}$ is the mechanical time consumption for the sub-project $\mathrm{k}$ of the project I, expressed in machinery hours. $\mathrm{Mu}_{\mathrm{I}, \mathrm{k}}$ represents the unit price of the machine for the sub-project $\mathrm{k}$ in the project $\mathrm{I}$, expressed in CNY. $\mathrm{Mt}_{\mathrm{I}, \mathrm{k}, \mathrm{l}}$ denotes the consumption of the material 1 for the sub-project $\mathrm{k}$ in the project $\mathrm{I}$. $\mathrm{Mp}_{\mathrm{I}, \mathrm{k}, \mathrm{l}}$ is the unit price of the material 1 for the sub-project $\mathrm{k}$ in the project $\mathrm{I}$, expressed in CNY.

In addition, the balanced deployment of resources is studied on the basis of the first level of resource usage, which is reflected in the form of the relative amount of resource inputs. The objective function of the second level objective can be expressed as the following:

$$
\min \mathrm{f}_{6}(\mathrm{x})=\mathrm{E}_{\mathrm{var}}=\sum_{\mathrm{n}=1}^{\mathrm{N}} \sum_{\mathrm{t}=1}^{\mathrm{T}}\left(\mathrm{R}_{\mathrm{n}}(\mathrm{t})-\overline{\mathrm{R}_{\mathrm{n}}}\right)^{2}
$$

where $E_{v a r}$ is the unbalanced value of resource inputs. $R_{n}(t)$ represents the amount of resources $n$ in work process $t . \overline{R_{n}}$ denotes the average value of resources $n$ in a certain construction period.

Ultimately, based on the five types of objective functions, this study establishes basic assumptions and sets constraints to the problems that need to be solved. Furthermore, there is also an interactive relationship between the objectives. For example, the consumption of resources is positively correlated with investment and negatively correlated with duration. Therefore, this study focuses on the multi-objective optimization of grid construction, developing algorithmic models and conducting example studies. 


\subsection{Multi-Objective Optimization Model of Investment Decision Making}

\subsubsection{Model Assumptions}

This paper mainly studies the new construction, reconstruction and expansion of power grids in certain areas. In order to facilitate the construction and solutions of the model and make them match the actual situation, some assumptions and simplifications need to be made to the problem:

(1) All new cables are laid in pipe trenches.

(2) The cost of grid decommissioning disposal is not in the scope of the study.

(3) Grid environmental impacts are not in the scope of the study.

(4) The unstable supply of electricity caused by higher levels is not considered in the study process.

(5) Impacts caused by changes in construction regulations, standards and codes during implementation are not considered.

(6) The investment, duration and resources under the different models studied in this paper are based on there being no problems with the quality and safety of the work. Therefore, quality and safety are not considered as separate factors. Similarly, risk is not a separate factor.

(7) The model is based on the approval of projects during the planning period. According to the characteristics of a project's approval, the site selection and land acquisition, and the substation and cable line construction within a certain area are different phases. Therefore, for the same substation and its associated cable laying, the site selection, substation and cable duct construction are studied separately as project sub-work. The sequence of construction is as follows: first, site selection; second, substation construction; third, cable laying.

(8) The study is based on the above construction steps and maintains a continuous implementation. From the moment of project initiation, it is assumed that there will be no interruptions or changes in the implementation process from project to project, and from job to job.

\subsubsection{Multi-Objective Optimization Model}

According to the above objective functions, the grid investment decisions need to consider the multi-objectives of the shortest construction cycle, minimum investment and reasonable deployment of resources. Meanwhile, logical and constraining conditions between objectives should be met. Furthermore, three types of objective functions can be integrated, namely site selection investment, construction investment and operation investment. As a result, the objective function of integrated investment can be set as follows:

$$
\mathrm{f}_{2}{ }^{*}(\mathrm{x})=\mathrm{f}_{2}(\mathrm{x})+\mathrm{f}_{3}(\mathrm{x})+\mathrm{f}_{4}(\mathrm{x})
$$

where $f_{2}{ }^{*}(x)$ is the objective function of integrated investment. $f_{2}(x)$ represents the objective function of site selection investment. $\mathrm{f}_{3}(\mathrm{x})$ denotes the objective function of construction investment. $f_{4}(x)$ represents the objective function of operation investment.

In addition, to ensure the normalization of these functions, the objective functions are unified to solve the minimum value in this study, and the model objective is expressed as follows:

$$
\min Z=F(x)=\left\{\alpha \cdot f_{1}(x), \beta \cdot f_{2}{ }^{*}(x), \gamma \cdot f_{6}(x)\right\}
$$

where $\alpha, \beta, \gamma$ are the weighting factors. $\mathrm{f}_{1}(\mathrm{x})$ represents the objective function of the construction cycle and $\mathrm{f}_{6}(\mathrm{x})$ denotes the objective function of the unbalanced value of resource inputs. Meanwhile, the weighting factors can be set by experienced grid engineers according to the characteristics of a given grid project. $\alpha \cdot f_{1}(x)$ is used to control the minimum project construction cycle within the planning cycle. $\beta \cdot f_{2}{ }^{*}(x)$ is used to achieve the minimum integrated investment during the planning period. $\gamma \cdot f_{6}(x)$ ensures the minimum unbalanced value of resource inputs, so as to balance the deployment of resources. 


\subsubsection{Constraint Conditions}

According to the objective functions, grid construction process and investment essentials, there are four types of constraints, namely the construction cycle constraint, site selection order constraint, investment order constraint and resource allocation constraint.

\section{(1) Construction cycle constraint}

Due to the constraints of the project cycle, the construction of the grid within the cycle is the total duration constraint, and should meet the following constraints:

$$
\mathrm{T}_{\text {total }} \leq \mathrm{P}_{\mathrm{t}}
$$

where $P_{t}$ is the power grid construction cycle, expressed in days.

\section{(2) Site selection order constraint}

According to the voltage level, the substation of a regional power grid project is set into $1,2, \ldots, \mathrm{L}, \ldots, \mathrm{N}$ levels. Meanwhile, the site selection of L-level substation cables and the L-level substation site selection are implemented simultaneously. Therefore, the site should be selected in accordance with the following conditions:

$$
\mathrm{T}_{\text {siteL }+1} \geq \mathrm{T}_{\text {siteL }}+\mathrm{d}_{\text {site }}
$$

where $T_{\text {siteL }+1}$ is the time span between the site selection approval of the $L+1$ substation and the construction completion of all regional power grid projects. Similarly, $\mathrm{T}_{\text {siteL }}$ represents the time span between the site selection approval of the L substation and the construction completion of all regional power grid projects. $d_{\text {site }}$ denotes the shortest time interval for the approval of the site selection of regional substations at different levels, $\mathrm{d}_{\text {site }} \geq 0$.

\section{(3) Construction investment order constraint}

The investment in power grid construction must be arranged according to the construction sequence. In other words, the investment needs to comply with the normal construction process, and the site selection investment, substation investment and cable investment should meet the following constraints:

$$
\begin{aligned}
& \mathrm{T}_{\text {sitel }} \geq \mathrm{T}_{\text {conI }}+\mathrm{d}_{\text {con }} \\
& \mathrm{T}_{\text {conI }} \geq \mathrm{T}_{\text {cabI }}+\mathrm{d}_{\text {cab }}
\end{aligned}
$$

where $T_{\text {siteI }}$ is the time span between the site selection approval of substation $I$ and the construction completion of all regional power grid projects. $\mathrm{T}_{\text {conI }}$ represents the time span between the start-up time of substation I construction and the completion of all regional power grid projects. $\mathrm{T}_{\mathrm{cabI}}$ denotes the time span between the start-up time of investment in the ancillary cables of the substations and the completion of all regional power grid projects. $\mathrm{d}_{\text {con }}$ is the shortest time interval between the start of substation site selection investment and the start of construction investment in the region, $\mathrm{d}_{\text {con }} \geq 0$. Similarly, $\mathrm{d}_{\text {cab }}$ represents the shortest time interval between the start of regional substation construction investment and the start of cable investment, $\mathrm{d}_{\mathrm{cab}} \geq 0$.

(4) Resource allocation constraint

Since the use of each resource must not exceed the maximum supply of the supplier, the amount of resources to be deployed must follow the following constraint:

$$
\mathrm{E}_{\mathrm{Im}} \geq \mathrm{U}_{\mathrm{Im}}
$$

where $\mathrm{E}_{\mathrm{Im}}$ is the maximum supply of resources $\mathrm{m}$ from the construction supplier for the project $\mathrm{I}$. $\mathrm{U}_{\mathrm{Im}}$ represents the maximum usage of resources $\mathrm{m}$ in project $\mathrm{I}$. 
Therefore, the above multi-objective functions and constraints constitute a multiobjective optimization model for regional power grid projects. Based on this model, the subsequent research is oriented towards the practical considerations of power grid investments, and the model is built and solved by methods of a multi-objective optimization algorithm, such as a genetic algorithm.

\subsection{Non-Dominated Sorting Genetic Algorithm with Elitist Strategy (NSGA-II)}

Genetic algorithms (GA) are a model developed according to the theory of biological evolution. They constitute a method of searching for the optimal solution by simulating the natural evolutionary law of the survival of the fittest. Firstly, a genetic algorithm should form an initial population. Second, in order to achieve superiority or inferiority, certain measures need to be imposed on the population in accordance with their environmental suitability. Finally, the problem to be solved is gradually approximated to the optimal solution by continuous evolution from generation to generation. Therefore, the basic steps can be summarized as the selection operator, the crossover operator and the variational operator [42].

Based on the concept of genetic algorithms, the non-dominated sorting genetic algorithm (NSGA) has received a lot of attention since it was proposed in 1994 after continuous improvements and innovations [43]. NSGA can use the non-dominated allocation program to convert multiple objectives into a fitness function. However, it is computationally complex and lacks elite strategies. In 2000, Deb proposed an improved genetic algorithm for fast non-dominated sorting (NSGA-II) [44]. Compared with the conventional genetic algorithm, NSGA-II has three characteristics:

(1) A fast non-dominated sorting method is used to reduce the computational complexity of the algorithm. This method is a cyclic process of grading adaptation values. First, the set of non-dominated solutions is found in the population, denoted as the first level, F1, and the individuals in it are removed from the whole population. Then, the remaining set of non-dominated solutions is found, which is noted as the second level, F2. According to this cycle, the whole population is stratified, and individuals in the same layer have the same non-dominated order.

(2) The concept of crowding distance is used, so that individuals in the same level are sorted selectively. On this basis, the crowding distances of individuals in each level can be calculated separately, and individuals with larger crowding distances can be selected. Ultimately, this ensures that individuals are evenly distributed in the target space so that the diversity of the population is maintained.

(3) If there is a parent population, $C_{i}$, and an offspring population, $D_{i}$, by introducing the elite strategy, elite individuals from the parent population $C_{i}$ are introduced into the offspring population $D_{i}$ to form a new population $C_{i+1}$, which fills $C_{i+1}$ from largest to smallest according to the crowding distance of each layer until the number of populations exceeds the size limit, which can prevent the absence of the Pareto optimal solution.

The NSGA-II algorithm extends the Pareto element to the whole Pareto domain according to the niche density to ensure population diversity, and introduces the elite policy to expand the sampling space. The basic flow of the algorithm is shown in Figure 1.

Similarly, the NSGA-II algorithm can be used for the multi-objective optimization of the power grid projects in a region. According to the steps of the NSGA-II algorithm, the power project objectives of schedule, investment and resource balance are found in the first generation. Then, a better set of solutions are fully determined through selection, crossover, variation and elite strategies.

Therefore, the following refined rules and processes are recommended when using the NSGA-II algorithm for power grid investments. 


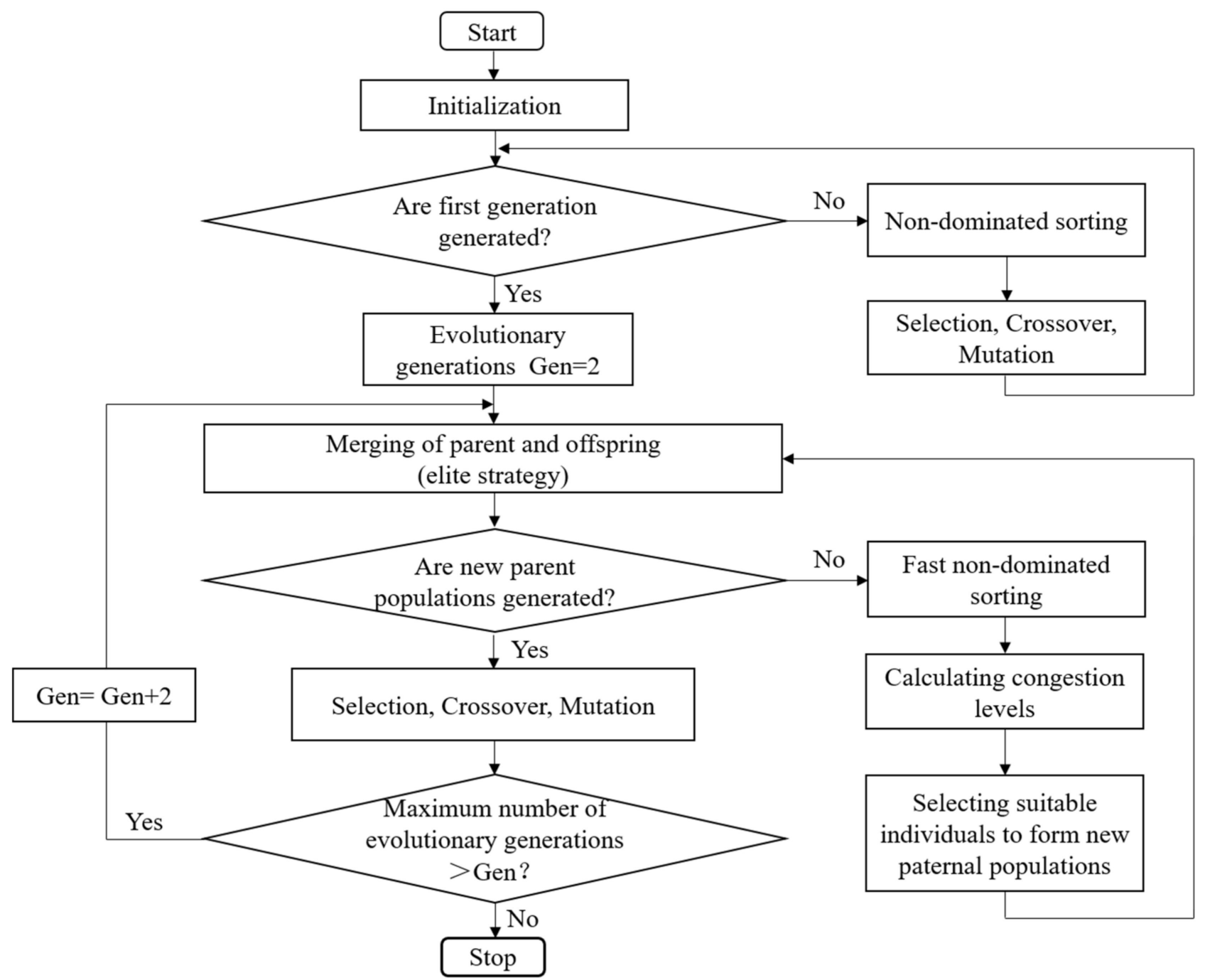

Figure 1. Flow chart of NSGA-II algorithm.

(1) Population initialization

In the NSGA-II algorithm, the most common forms of coding are binary coding and real number coding. According to the characteristics of the power grid projects, this study selects the form of real number coding. The main process is as follows.

Firstly, the initialization of the population should be carried out. Based on the investment process of the grid project, the coding rules are effectively applied. For the convenience of analysis of the coding rules, and taking the first five processes $\mathrm{A}, \mathrm{B}, \mathrm{C}$, $\mathrm{D}$ and $\mathrm{E}$ as an example, there are three possible patterns for each process, as shown in Figure 2 .

Each pattern for each process is coded as:

(1) A1, A2 and A3 correspond to 0, 1 and 2, respectively;

(2) B1, B2 and B3 correspond to 0, 1 and 2, respectively;

(3) $\mathrm{C} 1, \mathrm{C} 2$ and $\mathrm{C} 3$ correspond to 0,1 and 2, respectively;

(4) D1, D2 and D3 correspond to 0, 1 and 2, respectively;

(5) E1, E2 and E3 correspond to 0, 1 and 2, respectively.

This results in A1-B1-C1-D1-E1, A1-B2-C1-D1-E1, A1-B1-C2-D1-E1, . . , A3-B3-C3-D3-E3 corresponding to $0-0-0-0-0,0-1-0-0-0,0-0-1-0-0, \ldots, 2-2-2-2-2$; the population belongs to the set of multiple valid solutions. Therefore, for large-scale problems such as this study, when it is difficult to list all the solutions at one time, we can start searching from the population 
composed of some initial solutions and gradually find the optimal solution set according to the above rules.

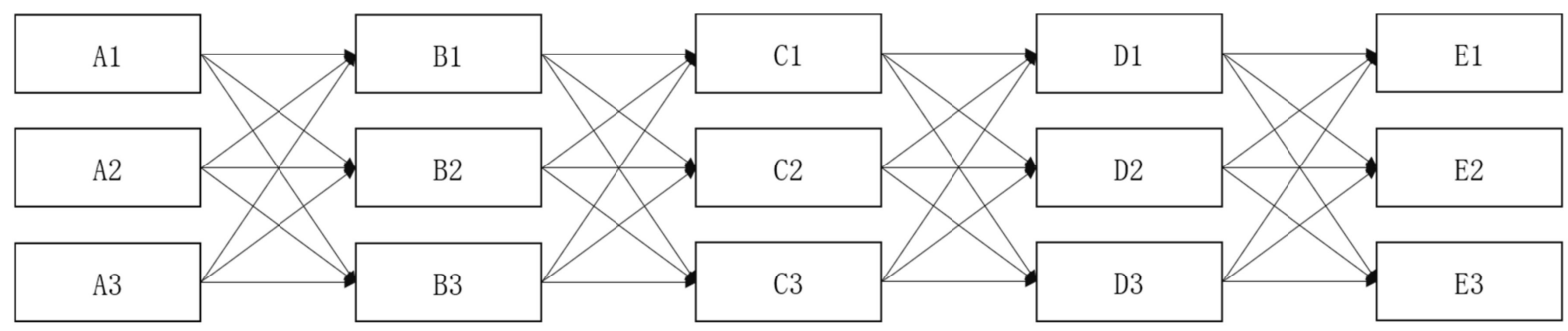

Figure 2. Analysis chart of encoding rule.

\section{(2) Elite Strategy}

As we know, the most important approach in elite strategies is non-dominated ordering. Using this approach for any two solutions $Z_{1}, Z_{2}$, if $Z_{1}$ is superior to $Z_{2}$ for all objectives in a multi-objective model, then $Z_{1}$ is defined to dominate $Z_{2}$. A solution of $Z_{1}$ is non-dominated if it is not dominated by other solutions. This can be done by the following specific steps (additionally, an analysis chart of this approach is shown in Figure 3).

Step 1: The upper limit on the number of individuals in the population is N. After the new population $Q_{g}$ is created in the generation $g$, it is merged with the parent $P_{g}$ to form the population $R_{\mathrm{g}}$.

Step 2: Then, the number of individuals in the population is $2 \mathrm{~N}$. An undominated sort of $R_{g}$ will result in a series of undominated sets $Z_{i}$. Furthermore, it must be ensured that the individuals contained in $Z_{1}$ in the common set of parents and offspring are the best in $R_{\mathrm{g}}$.

Step 3: $Z_{1}$ is put into the new parent population $P_{g+1}$; if the number of individuals in the new parent population is fewer than $\mathrm{N}$, then we continue to fill the next level of the non-dominated sets $Z_{2}, Z_{3}$, etc.

Step 4: When the size of the population exceeds $N$, assuming that the solution set fills the set $Z_{3}$ at this point, the crowding comparison algorithm is applied to the individuals in $Z_{3}$. Eventually, the number of $P_{g+1}$ individuals is brought to $\mathrm{N}$ after a comparison of the superiority of individuals. Those with insufficient individual strengths will be eliminated.

Step 5: Finally, new offspring populations $\mathrm{Q}_{\mathrm{g}+1}$ are generated by selection, crossover and mutation.

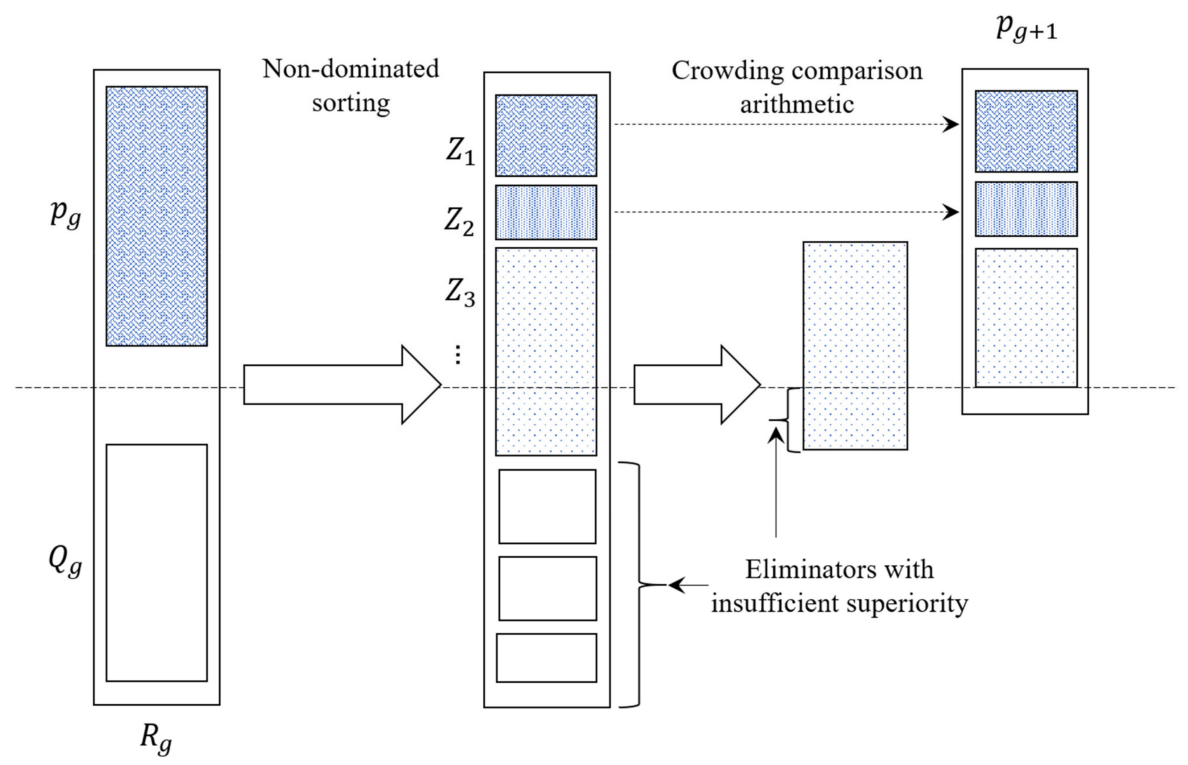

Figure 3. Analysis chart of elite strategy. 
In this study, the practical application of the elite strategy to the initialized populations can follow the following approach. Based on the four classes of solutions, 0-0-0-0-0, $0-1-0-0-0,0-0-1-0-0$ and $0-0-0-1-0$, and the optimization objective $\min Z=F(x)$ in the above assumptions, if the following assumptions exist:

$$
\begin{aligned}
& \mathrm{Z}(0-0-0-0-0)<\mathrm{Z}(0-1-0-0-0) \\
& \mathrm{Z}(0-0-0-0-0)<\mathrm{Z}(0-0-1-0-0) \\
& \mathrm{Z}(0-0-0-0-0)<\mathrm{Z}(0-0-0-1-0)
\end{aligned}
$$

then the solution $0-0-0-0-0$ is able to dominate these solutions, such as $0-1-0-0-0,0-0-1-0-0$ and $0-0-0-1-0$. In this case, $0-0-0-0-0$ is the first to fill in the new parent population, and the remaining non-dominated solutions are gradually incorporated in the same way, gradually forming a new parent population and generating a new offspring population through crossover and mutation.

(3) Solution of multi-objective optimization for the grid investment problem

According to the characteristics of multi-objective optimization, the optimization of one objective is often at the expense of the other objectives due to the mutual constraints of multiple objectives. As a result, it is difficult to meet all objectives optimally, so there will therefore be more than one solution, which presents a Pareto solution set. On the basis of the weight setting, all Pareto optimal solutions can be considered equally important. However, the multi-objective optimization of power grid projects is different from general projects. Factors including the stability of the electricity supply, the site of the substation and cable laying techniques all need to be considered. Therefore, based on the above-mentioned functions and model, an example analysis should be carried out for the multi-objective optimization of grid construction projects in order to verify the superiority of the model.

\section{Case Study}

\subsection{Data}

This case is based on the current situation and planning for the construction of a power grid in an area of the city W. As shown in the topology of Figure 4, five substations and several $110 \mathrm{kV}$ cable lines are planned to be built, which are shown as red dotted lines on the map. Meanwhile, the construction project is studied according to the following conditions.

(1) Three construction modes have been drawn up according to the needs of the grid company, namely the emergency mode, the rush mode and the general mode, which are illustrated by 1, 2 and 3, respectively, in Table 1.

(2) According to the characteristics of the grid construction implementation, essential factors that should be considered include: power stability, the construction cycle, construction resource transportation and deployment constraints. In addition, the close distance of the Yangtze River made the construction of the substation more difficult. Therefore, construction order is also a key factor in the investment decisions. The $\mathrm{XuD}$ substation, the FengHS substation, the WuTZ substation and their cables were construction with a high priority. The following constructions were the ZengJX substation, the ZhongBL substation and their cables, and finally the completion of the rest of the other cables.

Therefore, the construction sequence of the project was as follows. Substation site selection of $\mathrm{XuD}(\mathrm{A}) \rightarrow$ Construction of the $\mathrm{XuD}$ substation $(\mathrm{B}) \rightarrow$ Laying of cable lines from XuD to QinYL $(\mathrm{C}) \rightarrow$ Laying of cable lines from XuD to WangJT (D) $\rightarrow$ Substation site selection of FengHS (E) $\rightarrow$ Construction of the FengHS substation $(\mathrm{F}) \rightarrow$ Laying of cable lines from FengHS to NianYT $(\mathrm{G}) \rightarrow$ Laying of cable lines from FengHS to ShaH $(\mathrm{H}) \rightarrow$ Substation site selection of WuTZ (I) $\rightarrow$ Construction of the WuTZ substation $(\mathrm{J}) \rightarrow$ Laying of cable lines from WuTZ to NianYT $(\mathrm{K}) \rightarrow$ Laying of cable lines from WuTZ to ZiYH (L) 
$\rightarrow$ Substation site selection of ZengJX $(\mathrm{M}) \rightarrow$ Construction of the ZengJX substation $(\mathrm{N})$ $\rightarrow$ Laying of cable lines from ZengJX to $\mathrm{XuD}(\mathrm{O}) \rightarrow$ Laying of cable lines from ZengJX to YouYGJ (P) $\rightarrow$ Substation site selection of ZhongBL (Q) $\rightarrow$ Construction of the ZhongBL substation $(\mathrm{R}) \rightarrow$ Laying of cable lines from ZhongBL to TiYG $(\mathrm{S}) \rightarrow$ Laying of cable lines from ZhongBL to CaiJZ (T) $\rightarrow$ Laying of cable lines from PengLY to FuJP (U) $\rightarrow$ Laying of cable lines from FuJP to LuoJS (V) $\rightarrow$ Laying of cable lines from CaijZ to ChaG (W), where $\mathrm{U}$ and $\mathrm{V}$ were implemented simultaneously.

(3) The construction period, investment, resource utilization and quantity of works were mainly based on the detailed rules for budget estimate of power transmission and transformation projects (2018 Edition), the cost analysis report for power transmission and transformation projects of $\mathrm{H}$ province (2017 Edition, 2018 Edition, 2019 Edition) [45], the budgetary quotas for power construction projects and documents for the approval of design estimates for grid projects in H Province. In addition, according to the characteristics of the approval of the preliminary design of various projects in H province in 2018 and 2019, the power grid construction substation and cable projects were approved and constructed separately. Therefore, if the resource inputs are unified as workdays as the object of study, the relevant data for the construction duration, planned investment and resource inputs of this case are shown in Table 1.

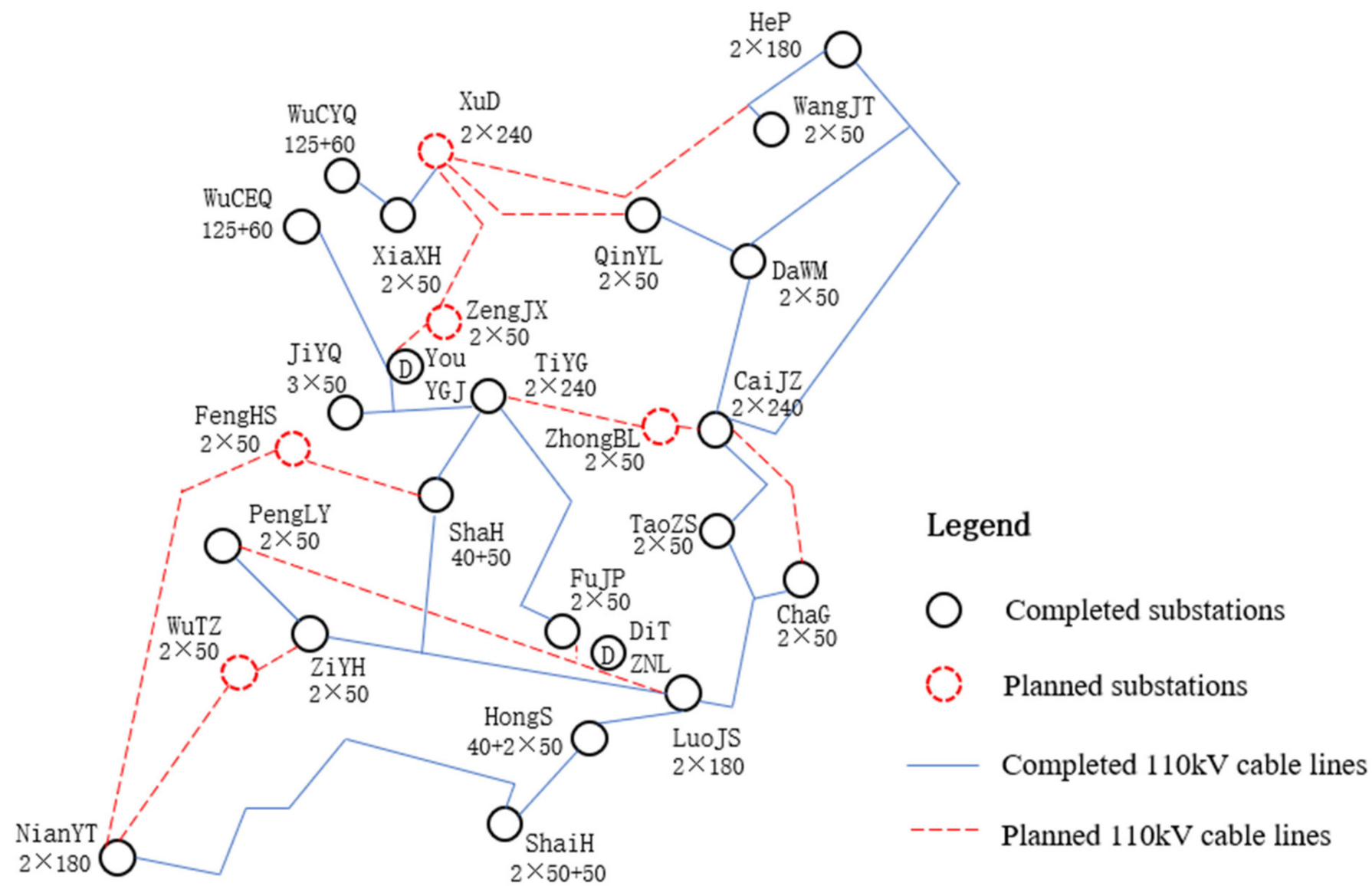

Figure 4. Topological map of power grid in an area of city W. 
Table 1. Relevant parameter information for the case of power grid investment.

\begin{tabular}{|c|c|c|c|c|c|c|c|c|c|c|c|}
\hline Sub-Projects & Subsequent Projects & Patterns & $\begin{array}{l}\text { Construction Cycle } \\
\text { (Days) }\end{array}$ & $\begin{array}{l}\text { Investment } \\
(¥ 10,000)\end{array}$ & $\begin{array}{l}\text { Resource Input } \\
\text { (Workdays) }\end{array}$ & Sub-Projects & Subsequent Projects & Patterns & $\begin{array}{l}\text { Construction Cycle } \\
\text { (Days) }\end{array}$ & $\begin{array}{l}\text { Investment } \\
(\because 10,000)\end{array}$ & $\begin{array}{l}\text { Resource Input } \\
\text { (Work Days) }\end{array}$ \\
\hline & & 1 & 100 & 3306 & 28,652 & & & 1 & 24 & 571 & 4945 \\
\hline \multirow[t]{3}{*}{ A } & B & 2 & 130 & 2677 & 23,200 & M & $\mathrm{N}$ & 2 & 30 & 507 & 4395 \\
\hline & & 3 & 150 & 2320 & 20,107 & & & 3 & 35 & 483 & 4186 \\
\hline & & 1 & 220 & 28,018 & 242,825 & & & 1 & 70 & 4035 & 34,969 \\
\hline \multirow[t]{3}{*}{ B } & C & 2 & 280 & 20,013 & 173,446 & $\mathrm{~N}$ & $\mathrm{O}$ & 2 & 87 & 3246 & 28,136 \\
\hline & & 3 & 320 & 17,511 & 151,765 & & & 3 & 100 & 2824.4 & 24,478 \\
\hline & & 1 & 25 & 381 & 3306 & & & 1 & 60 & 905 & 7843 \\
\hline \multirow[t]{3}{*}{ C } & $\mathrm{D}$ & 2 & 32 & 314 & 2719 & $\mathrm{O}$ & $\mathrm{P}$ & 2 & 78 & 773 & 6703 \\
\hline & & 3 & 37 & 286 & 2475 & & & 3 & 93 & 720.8 & 6247 \\
\hline & & 1 & 6 & 92 & 798 & & & 1 & 15 & 220 & 1903 \\
\hline \multirow[t]{3}{*}{ D } & E & 2 & 8 & 73 & 630 & $\mathrm{P}$ & $\mathrm{Q}$ & 2 & 20 & 183 & 1586 \\
\hline & & 3 & 9 & 68 & 589 & & & 3 & 23 & 176.8 & 1532 \\
\hline & & 1 & 32 & 749 & 6493 & & & 1 & 20 & 587 & 5086 \\
\hline \multirow[t]{3}{*}{ E } & $\mathrm{F}$ & 2 & 45 & 561 & 4860 & $\mathrm{Q}$ & $\mathrm{R}$ & 2 & 26 & 502 & 4347 \\
\hline & & 3 & 55 & 483 & 4186 & & & 3 & 30 & 483 & 4186 \\
\hline & & 1 & 100 & 4170 & 36,140 & & & 1 & 62 & 3804 & 32,966 \\
\hline \multirow{3}{*}{$\mathrm{F}$} & G & 2 & 130 & 3055 & 26,476 & $\mathrm{R}$ & $\mathrm{S}$ & 2 & 78 & 3024 & 26,204 \\
\hline & $G$ & 3 & 150 & 2647.6 & $\begin{array}{l}20,970 \\
22,946\end{array}$ & K & 3 & 3 & 90 & 2620.4 & $\begin{array}{l}20,710 \\
22,710\end{array}$ \\
\hline & & 1 & 50 & 720 & 6240 & & & 1 & 65 & 869 & 7535 \\
\hline \multirow[t]{3}{*}{ G } & $\mathrm{H}$ & 2 & 64 & 625 & 5417 & S & $\mathrm{T}$ & 2 & 82 & 766 & 6636 \\
\hline & & 3 & 76 & 584.8 & 5068 & & & 3 & 95 & 734.4 & 6365 \\
\hline & & 1 & 40 & 625 & 5413 & & & 1 & 31 & 451 & 3908 \\
\hline \multirow[t]{2}{*}{$\mathrm{H}$} & I & 2 & 53 & 524 & 4539 & $\mathrm{~T}$ & UV & 2 & 40 & 388 & 3365 \\
\hline & & 3 & 63 & 489.6 & 4243 & & & 3 & 47 & 367.2 & 3182 \\
\hline \multirow{2}{*}{ I } & & 3 & 45 & 483 & 4186 & & & 3 & 67 & 516.8 & 4479 \\
\hline & & 1 & 90 & 4799 & 41,594 & & & 1 & 60 & 821 & 7111 \\
\hline \multirow[t]{3}{*}{ J } & $\mathrm{K}$ & 2 & 115 & 3577 & 31,002 & V & W & 2 & 78 & 743 & 6436 \\
\hline & & 3 & 130 & 3164.4 & 27,425 & & & 3 & 91 & 707.2 & 6129 \\
\hline & & 1 & 25 & 378 & 3277 & & & 1 & 31 & 426 & 3691 \\
\hline \multirow[t]{3}{*}{ K } & $\mathrm{L}$ & 2 & 33 & 318 & 2758 & W & - & 2 & 40 & 388 & 3365 \\
\hline & & 3 & 39 & 299.2 & 2593 & & & 3 & 47 & 367.2 & 3182 \\
\hline & & 1 & 21 & 329 & 2851 & & & & & & \\
\hline \multirow[t]{2}{*}{$\mathrm{L}$} & M & 2 & 28 & 274 & 2375 & & & & & & \\
\hline & & 3 & 33 & 258.4 & 2239 & & & & & & \\
\hline
\end{tabular}




\subsection{Solution Set Based on NSGA-II Algorithm Model}

According to the multi-objective optimization algorithm model of power grid investment, the weight coefficients $\alpha, \beta$ and $\gamma$ of the three types of objectives were equally valued in this case. Meanwhile, the investment order was site selection first, substation construction second and cable construction last.

The relevant data were entered into the NSGA-II algorithm and modelled using the Python programming language. The algorithm was integer coded, the population size was set to 40 , the maximum number of iterations was 300 and the probabilities of crossover and variation were 0.85 and 0.15 , respectively. According to the above rules, the program is run on an assembled desktop computer configured with an Intel(R) CORE(TM) i7-8700 processor with 32 GB RAM in Beijing, China. The results of the operations are shown in Table 2.

Table 2. Pareto solution set of NSGA-II.

\begin{tabular}{|c|c|c|c|c|c|c|c|}
\hline Order & $\begin{array}{l}\text { Total Construction } \\
\text { Cycle (Days) }\end{array}$ & $\begin{array}{l}\text { Total Investment } \\
(¥ 10,000)\end{array}$ & $\begin{array}{l}\text { Unbalanced Value of } \\
\text { Resource Inputs }\end{array}$ & Order & $\begin{array}{l}\text { Total Construction } \\
\text { Cycle (Days) }\end{array}$ & $\begin{array}{l}\text { Total Investment } \\
\quad(¥ 10,000)\end{array}$ & $\begin{array}{l}\text { Unbalanced Value of } \\
\text { Resource Inputs }\end{array}$ \\
\hline 1 & 1427 & 36,780 & 364,410 & 21 & 1231 & 44,166 & 428,745 \\
\hline 2 & 1335 & 39,178 & 387,107 & 22 & 1445 & 36,678 & 365,304 \\
\hline 3 & 1223 & 50,079 & 481,222 & 23 & 1562 & 35,714 & 373,746 \\
\hline 4 & 1259 & 42,974 & 418,086 & 24 & 1496 & 36,115 & 369,662 \\
\hline 5 & 1314 & 40,265 & 398,206 & 25 & 1312 & 40,284 & 398,038 \\
\hline 6 & 1200 & 51,203 & 492,995 & 26 & 1365 & 38,054 & 377,004 \\
\hline 7 & 1269 & 41,683 & 406,896 & 27 & 1409 & 37,169 & 368,108 \\
\hline 8 & 1191 & 51,325 & 491,933 & 28 & 1267 & 42,854 & 418,605 \\
\hline 9 & 1251 & 43,320 & 422,554 & 29 & 1514 & 35,983 & 370,802 \\
\hline 10 & 1488 & 36,226 & 368,704 & 30 & 1358 & 38,389 & 381,612 \\
\hline 11 & 1229 & 44,185 & 428,577 & 31 & 1215 & 50,199 & 480,703 \\
\hline 12 & 1536 & 35,936 & 372,333 & 32 & 1367 & 38,151 & 376,617 \\
\hline 13 & 1315 & 39,692 & 389,643 & 33 & 1323 & 39,581 & 390,601 \\
\hline 14 & 1358 & 38,389 & 381,612 & 34 & 1227 & 49,796 & 477,209 \\
\hline 15 & 1287 & 40,884 & 400,302 & 35 & 1284 & 41,476 & 408,697 \\
\hline 16 & 1214 & 50,772 & 489,266 & 36 & 1207 & 50,859 & 487,984 \\
\hline 17 & 1549 & 35,902 & 372,113 & 37 & 1184 & 51,983 & 499,757 \\
\hline 18 & 1345 & 38,577 & 379,979 & 38 & 1377 & 37,766 & 372,955 \\
\hline 19 & 1258 & 43,217 & 423,448 & 39 & 1244 & 43,978 & 430,378 \\
\hline 20 & 1453 & 36,558 & 365,823 & 40 & 1475 & 36,385 & 367,317 \\
\hline
\end{tabular}

According to the genetic algorithm of the elite strategy, 40 scenarios were obtained for the last generation population. It can be seen that the total duration spanned from 1184 days to 1562 days, and the total investment ranged from 357.14 million CNY to 519.83 million CNY.

Therefore, it can be determined that the total construction period and the total investment show a negative correlation, and the solution with a larger construction period had a relatively better savings investment. In addition, the unbalanced value of resource inputs was the measure of resource input uniformity, and the smaller value of the variable of input indicates that the more balanced the input, the smaller the risk of causing instability to the power supply. The spatial distribution of Pareto frontier solutions after 300 iterations is shown in Figure 5.

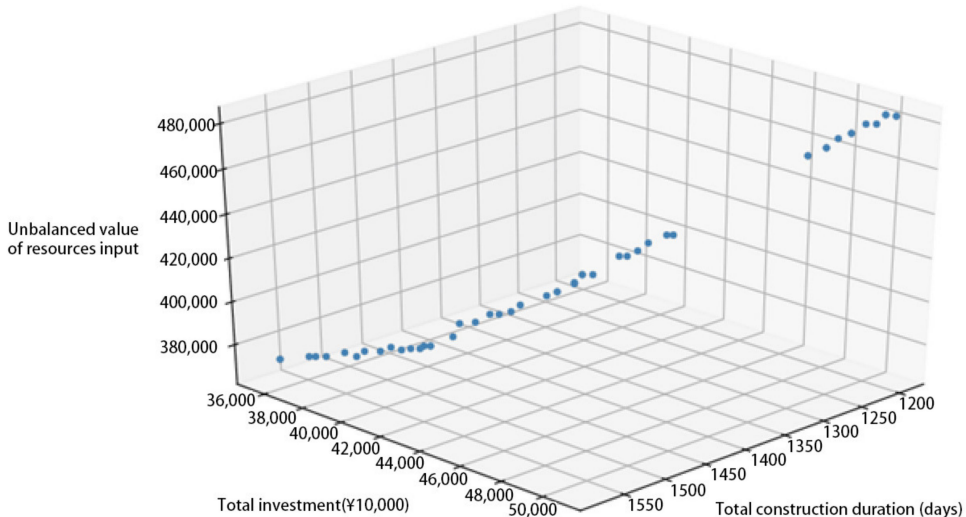

Figure 5. Spatial distribution of optimal Pareto solutions after 300 iterations. 


\subsection{Comparative Analysis of Multi-Objective Optimization Algorithms}

In order to further verify the applicability of the algorithms, NSGA-II, PSO (particle swarm optimization) and the GA (genetic algorithm) were compared and analyzed for grid investment decision calculations. Each algorithm completed 300 iterations of the optimal solution, and to avoid serendipity, each algorithm was computed three times. The number of optimal solution populations was taken to be 40 for each algorithm and each calculation. Subsequently, the total individuals of the optimal solution of the 3-class algorithm were considered as a new population of the number 360, and this population was further subjected to an undominated sort, containing a total of 220 undominated solutions. On this basis, the number and proportion of optimal solutions corresponding to the Pareto frontier for these three classes of algorithms in this new population could then be analyzed.

In addition, the optimal number of iterations of the three algorithms can be measured using an enumeration experiment. Firstly, the optimal individual variation characteristics of the three algorithms with $100,150 \ldots$ and 300 iterations were studied, respectively. When the individual variation characteristics are not obvious, the algorithm can be regarded as having converged to obtain the optimal solution or local optimal solution. Secondly, according to the convergence of the three algorithms, the interval of iteration times was further refined. For example, if the GA converges within 100 iterations, the number of iterations is further divided into 30,50 and 80 in experiments, and so on, until the optimal number of iterations is obtained. The program is run on a PC configured with an Intel(R) CORE(TM) i7-8700 processor with 32 GB RAM. It can be found that the times of searching for the optimal solution are $2.2 \mathrm{~s}$ for NSGA-II, $3.8 \mathrm{~s}$ for PSO and $1.6 \mathrm{~s}$ for GA, respectively. The number of optimal solutions, the ratio and the optimal number of iterations for the three algorithms are shown in Table 3.

Table 3. Comparison of NSGA-II, PSO and GA.

\begin{tabular}{cccc}
\hline Multi-Objective Optimization Methods & Optimal Number of Iterations & Number of Optimal Solutions & Optimal Solution Ratio \\
\hline NSGA-II & 85 & 81 & $36.82 \%$ \\
PSO & 155 & 83 & $37.73 \%$ \\
GA & 75 & 56 & $25.45 \%$ \\
\hline
\end{tabular}

We can see that in terms of convergence speed, GA > NSGA-II > PSO; however, by comparing the number of optimal solutions, the GA appeared to be premature and its ability to search for the optimal solution set decreased due to the rapid convergence. Meanwhile, PSO had a higher number of iterations. Without considering the influence of operation efficiency, PSO also had high-quality solutions. In contrast, NSGA-II had a higher operation efficiency and a higher quality of solutions. Therefore, NSGA-II was determined to be more suitable for the multi-objective optimization of power grid multi-project investment in a certain area.

\section{Discussion}

According to the comparative analysis of the algorithms, the NSGA-II algorithm is suitable for multi-objective optimization in investment decisions for power grids. For power grid projects in a certain area, the three main objectives of construction duration, investment and the unbalanced value of resource inputs did not have a dominant relationship with each other. Therefore, depending on the objectives, an implementation model can be chosen that suits the current state of grid projects in a given region. The following scenario is the Pareto solution set selection based on two types of projects with different goal focuses.

(1) Scenario 1: The construction cycle is the highest priority. If it is difficult to avoid the power grid project's impact on electricity consumption in urban areas, the construction period needs to be as short as possible. As a result, on the basis of ensuring the quality of the power grid, the project investment and the balance of resource inputs are regarded as non-priority factors. Then, the scheme with less of a construction cycle 
should be selected as the actual implementation scheme from the Pareto optimal solution. This is shown in Table 4.

Table 4. Pareto solution set with priority of guaranteeing construction period.

\begin{tabular}{cccc}
\hline No. & Construction Cycle (Days) & $\begin{array}{c}\text { Construction Investment } \\
(\mathbf{1 0 , 0 0 0} \text { CNY) }\end{array}$ & $\begin{array}{c}\text { Unbalanced Value of } \\
\text { Resource Inputs }\end{array}$ \\
\hline 1 & 1200 & 51,203 & 492,995 \\
2 & 1191 & 51,325 & 491,933 \\
3 & 1207 & 50,859 & 487,984 \\
4 & 1184 & 51,983 & 499,757 \\
\hline
\end{tabular}

(2) Scenario 2: The construction investment is the highest priority. If the power grid projects have the following characteristics: a sufficient construction period, are relatively simple to implement and have little impact on the regional power supply, then these projects can focus on controlling investment and ensuring a balanced input of resources, and the Pareto optimal set of solutions can be chosen, as shown in Table 5.

Table 5. Pareto solution set with priority of reducing investment.

\begin{tabular}{|c|c|c|c|}
\hline No. & Construction Period (Days) & $\begin{array}{l}\text { Construction Investment } \\
\qquad(¥ 10,000)\end{array}$ & $\begin{array}{l}\text { Unbalanced Value of } \\
\text { Resource Inputs }\end{array}$ \\
\hline 1 & 1536 & 35,936 & 372,333 \\
\hline 2 & 1549 & 35,902 & 372,113 \\
\hline 3 & 1562 & 35,714 & 373,746 \\
\hline 4 & 1514 & 35,983 & 370,802 \\
\hline
\end{tabular}

In summary, in order to ensure rational investment decisions for a power grid project in a given region, the substation location, construction and cable laying need to be critically considered in terms of investment, the construction cycle and the resource inputs. Similarly, the decision options can be adjusted by adjusting the values of the weight coefficients $\alpha, \beta$ and $\gamma$ of the objectives, and by providing a wide choice of practice options. Therefore, the NSGA-II algorithm for the multi-objective optimization of grid projects meets the needs of the investment decision objectives and is able to obtain relatively high-quality solutions with guaranteed operational efficiency.

\section{Conclusions}

In recent years, the proportion of China's power grid investment in the whole power project has continued to increase year by year, which has also led to new requirements for the investment methods of power projects. In addition, power grid investment can be regarded as a research problem for collaborative decision-making, with various stakeholders and objectives involved. However, it is difficult to use traditional grid project investment models and management modes to select construction solutions that meet multi-objectives, and it is also difficult to optimize the comprehensive benefits of a given project. Therefore, this paper uses a multi-objective optimization approach to study grid investment projects, and introduces the NSGA-II algorithm to solve the model. According to the results, we conclude as follows:

(1) An investment decision-making method was introduced in power grid projects. This method can balance the duration, investment and resource deployment of the power grid construction. Furthermore, this method is proven to be feasible and effective by the case, and the optimal solution can be selected from the solution set according to various project-scenarios. This approach can provide a decision-making reference for the implementation of power grid projects.

(2) Based on the characteristics of power grid construction, firstly, the target factors of power grid investment were analyzed and quantified. Then, a corresponding multiobjective model was established. The model assumptions and constraints ensured the model conformed to actual power grid projects, and the results were obtained 
directly through quantitative calculation. Eventually, this will make the conclusions more objective and credible.

(3) The advantages of genetic algorithms in multi-objective optimization were analyzed. According to the objectives of power grid investment projects, the applicability, calculation logic and calculation steps of the NSGA-II algorithm for power grid projects were studied. The algorithm effectively simplifies the calculation process, and is easy to realize by computer programming. Therefore, it can provide a decision-making basis for the multi-objective optimization of power grid investment projects.

(4) According to the further study of the applicability of the NSGA-II algorithm, critical analysis was carried out. On the one hand, the advantages of NSGA-II were compared and analyzed through three types of algorithms. On the other hand, the selection of a multi-objective optimal solution set in different scenarios was proposed. Therefore, the algorithm is suitable for power grid practice projects.

From the perspective of project management, this study applies the new multiobjective optimization method to power grid investment decision-making. In the planning stages of power grid projects, this method provides a theoretical basis and practical reference for exploring collaborative decision making and efficient management. It can also provide reference for relevant engineering decisions in China and other countries. Therefore, in future research, scholars can study the objective factors of different types of engineering projects, and can use the methods of multi-objective optimization to find the most suitable solution set.

Author Contributions: Conceptualization, L.G.; Data collection, L.G.; Data curation, C.L.; Funding acquisition, L.G.; Investigation, C.L.; Methodology, L.G. and Z.-Y.Z.; Project administration, L.G.; Resources, C.L.; Software, L.G.; Supervision, Z.-Y.Z.; Writing—original draft, L.G.; Writing-review and editing, Z.-Y.Z. All authors have read and agreed to the published version of the manuscript.

Funding: This research was funded by the Fundamental Research Funds for the Central Universities, grant number ZY20210317.

Institutional Review Board Statement: Not applicable.

Informed Consent Statement: Not applicable.

Acknowledgments: This paper is supported by the Fundamental Research Funds for the Central Universities (No. ZY20210317). The authors would like to express their gratitude for the support of these funding authorities.

Conflicts of Interest: The authors declare no conflict of interest.

\section{References}

1. National Power Grid Corp of China. Notice on Further Strict Control of Grid Investment (No. 826). 2019-12-3. (In Chinese). Available online: https:/ / guangfu.bjx.com.cn/news/20191202/1025242.shtml (accessed on 28 November 2021).

2. Southern Power Grid Corp of China. Optimize Investment and Cost Control Measures (2019 Edition). 2019-11-26. (In Chinese). Available online: http://www.csg.cn/xwzx/2019/gsyw/201911/t20191126_306175.html (accessed on 28 November 2021).

3. Zhao, Z.Y.; Lv, Q.L.; You, W.Y.; GAO, Y. An Evaluation Index Model of Construction Cost for 35 kV Transmission Lines in Rural Power Network. Power Syst. Technol. 2008, 32, 96-100.

4. Zhao, H.R.; Wang, H.; Han, Y. Investment optimization for grid construction projects and aid decision-making systems for grid investment. East China Electr. Power 2007, 35, 23-25.

5. He, Y.X.; Jiao, J.; Chen, R.J.; Shu, H. The optimization of Chinese power grid investment based on transmission and distribution tariff policy: A system dynamics approach. Energy Policy 2018, 113, 112-122. [CrossRef]

6. Schachter, J.A.; Mancarella, P. A critical review of Real Options thinking for valuing investment flexibility in Smart Grids and low carbon energy systems. Renew. Sustain. Energy Rev. 2016, 56, 261-271. [CrossRef]

7. Zhu, Y.J. Research on Investment Allocation Optimization Model of Power Grid Enterprises Based on Regional Development. Power Energy 2016, 37, 704-708. (In Chinese)

8. Qian, M.A.; Wang, Z.; Pan, X.; Liu, X. Evaluation method of power grid investment decision based on utility function under new electricity reform environment. Electr. Power Autom. Equip. 2019, 39, 198-204. (In Chinese) 
9. Chang, Y.; Liu, C.; Liu, M.; Liu, W.; Liu, Z.; Zhang, H.; Zheng, Y. Differentiation degree combination weighting method for investment decision-making risk assessment in power grid construction projects. Glob. Energy Interconnect. 2019,2 , 465-477. [CrossRef]

10. Zhang, S.; Du, M.; Tong, J.; Li, Y.F. Multi-objective optimization of maintenance program in multi-unit nuclear power plant sites. Reliab. Eng. Syst. Saf. 2019, 188, 532-548. [CrossRef]

11. Salehi, S.; Mahmoudi, S.M.S.; Yari, M.; Rosen, M.A. Multi-objective optimization of two double-flash geothermal power plants integrated with absorption heat transformation and water desalination. J. Clean. Prod. 2018, 195, 796-809. [CrossRef]

12. Özahi, E.; Tozlu, A.; Abuşoğlu, A. Thermo-economic multi-objective optimization of an organic Rankine cycle (ORC) adapted to an existing solid waste power plant. Energy Convers. Manag. 2018, 168, 308-319. [CrossRef]

13. Wang, C.; Olsson, G.; Liu, Y. Coal-fired power industry water-energy-emission nexus: A multi-objective optimization. J. Clean. Prod. 2018, 203, 367-375. [CrossRef]

14. Fadaee, M.; Radzi, M.A.M. Multi-objective optimization of a stand-alone hybrid renewable energy system by using evolutionary algorithms: A review. Renew. Sustain. Energy Rev. 2012, 16, 3364-3369. [CrossRef]

15. Chen, D.; Gong, Q.; Zhang, M.; Liu, D.; Shao, Q. Multi-objective optimal dispatch in wind power integrated system incorporating energy-environmental efficiency. Proc. Chin. Soc. Electr. Eng. 2011, 31, 10-17.

16. Javadi, M.S.; Saniei, M.; Mashhadi, R.H.; Gutiérrez-Alcaraz, G. Multi-objective expansion planning approach: Distant wind farms and limited energy resources integration. Renew. Power Gener. IET 2013, 7, 652-668. [CrossRef]

17. Javadi, M.S.; Razavi, S.E.; Ahmadi, A.; Siano, P. A novel approach for distant wind farm interconnection: Iran South-West wind farms integration. Renew. Energy 2019, 140, 737-750. [CrossRef]

18. Javadi, M.S.; Nezhad, A.E. Multi-objective, multi-year dynamic generation and transmission expansion planning-renewable energy sources integration for Iran's National Power Grid. Eur. Trans. Electr. Power Eng. 2019, 29, e2810.1-e2810.21. [CrossRef]

19. Anand, H.; Narang, N.; Dhillon, J.S. Multi-objective combined heat and power unit commitment using particle swarm optimization. Energy 2019, 172, 794-807. [CrossRef]

20. Zhang, G.; Wu, B.; Maleki, A.; Zhang, W. Simulated annealing-chaotic search Algorithm based optimization of reverse osmosis hybrid desalination system driven by wind and solar energies. Sol. Energy 2018, 173, 964-975. [CrossRef]

21. Li, C.S.; Wang, W.; Chen, D. Multi-objective complementary scheduling of hydro-thermal-RE power system via a multi-objective hybrid grey wolf optimizer. Energy 2019, 171, 241-255. [CrossRef]

22. Wang, J.; Yang, W.; Du, P.; Li, Y. Research and application of a hybrid forecasting framework based on multi-objective optimization for electrical power system. Energy 2018, 148, 59-78. [CrossRef]

23. Li, Q.; Sun, L.; Bao, L. Enhanced index tracking based on multi-objective immune algorithm. Expert Syst. Appl. 2011, 38, 6101-6106. [CrossRef]

24. Wu, X.; Yang, Y.; Han, S.; Zhao, Z.L.; Fang, P.; Gao, Q.Y. Multi-objective optimization method for nuclear reactor radiation shielding design based on PSO algorithm. Ann. Nucl. Energy 2021, 160, 108404. [CrossRef]

25. Chang, J.; Li, Z.; Huang, Y.; Yu, X.; Jiang, R.C.; Huang, R.; Yu, X.L. Multi-objective optimization of a novel combined cooling, dehumidification and power system using improved M-PSO algorithm. Energy 2022, 239, 122487. [CrossRef]

26. Guo, X.; Ji, M.; Zhao, Z.; Wen, D.; Zhang, W. Global path planning and multi-objective path control for unmanned surface vehicle based on modified particle swarm optimization (PSO) algorithm. Ocean. Eng. 2020, 216, 107693. [CrossRef]

27. Okasha, N.M.; Dan, M.F. Lifetime-oriented multi-objective optimization of structural maintenance considering system reliability, redundancy and life-cycle cost using GA. Struct. Saf. 2009, 31, 460-474. [CrossRef]

28. Verma, M.; Ghritlahre, H.K.; Chaurasiya, P.K.; Ahmed, S.; Bajpai, S. Optimization of Wind Power Plant Sizing and Placement by the Application of Multi-Objective Genetic Algorithm (GA) in Madhya Pradesh, India. Sustain. Comput. Inform. Syst. 2021, 32, 1006906. [CrossRef]

29. Ghersi, D.E.; Loubar, K.; Amoura, M.; Tazerout, M. Multi-objective optimization of micro co-generation spark-ignition engine fueled by biogas with various $\mathrm{CH}_{4} / \mathrm{CO}_{2}$ content based on GA-ANN and decision-making approaches. J. Clean. Prod. 2021, 329, 129739. [CrossRef]

30. Gentils, T.; Wang, L.; Kolios, A. Integrated structural optimization of offshore wind turbine support structures based on finite element analysis and genetic algorithm. Appl. Energy 2017, 199, 187-204. [CrossRef]

31. Ershadi, H.; Karimipour, A. Present a multi-criteria modeling and optimization (energy, economic and environmental) approach of industrial combined cooling heating and power (CCHP) generation systems using the genetic algorithm, Case study: A tile factory. Energy 2018, 149, 286-295. [CrossRef]

32. Tomoiagă, B.; Chindriş, M.; Sumper, A.; Sudria-Andreu, A.; Villafafila-Robles, R. Pareto Optimal Reconfiguration of Power Distribution Systems Using a Genetic Algorithm Based on NSGA-II. Energies 2013, 6, 1439-1455. [CrossRef]

33. Mahmoudimehr, J.; Parvin, S. A novel multi-objective Dynamic Programming optimization method: Performance management of a solar thermal power plant as a case study. Energy 2019, 168, 796-814. [CrossRef]

34. Xu, C.B.; Ke, Y.M.; Li, Y.B.; Chu, H.; Wu, Y.N. Data-driven configuration optimization of an off-grid wind/PV/hydrogen system based on modified NSGA-II and CRITIC-TOPSIS—ScienceDirect. Energy Convers. Manag. 2020, 215, 112892. [CrossRef]

35. Zhang, D.B.; Liu, J.W.; Jiao, S.F.; Tian, H.; Lou, C.Z.; Zhou, Z.H.; Zhang, J.; Wang, C.D.; Zuo, J. Research on the configuration and operation effect of the hybrid solar-wind-battery power generation system based on NSGA-II. Energy 2019, $189,116121$. [CrossRef] 
36. Xiao, W.; Cheng, A.; Li, S.; Jiang, X.B.; Ruan, X.H. A multi-objective optimization strategy of steam power system to achieve standard emission and optimal economic by NSGA-II. Energy 2021, 232, 120953. [CrossRef]

37. Gao, L. Research on the Model and Application of Multi-Agent Collaborative Decision-Making of Power Grid Construction Projects; North China Electric Power University: Beijing, China, 2020. (In Chinese)

38. National People's Congress. Land Management Law of the People's Republic of China. 2020-1-1. (In Chinese). Available online: http:/ / www.bjtzh.gov.cn/tzzfxxgk/c109720/202009/1316875.shtml (accessed on 28 November 2021).

39. Beijing Municipal People's Government. Beijing Construction Land Acquisition Compensation and Resettlement Measures. 2004-5-21. (In Chinese). Available online: http://www.beijing.gov.cn/zhengce/zhengcefagui/201905/t20190522_56579.html (accessed on 28 November 2021).

40. National Energy Administration. Budgeting and Calculation Standards for Power Grid Construction; China Electric Power Press: Beijing, China, 2020; p. 3. (In Chinese)

41. General Administration of Electricity Engineering Costs and Quotations. China Electrical Engineering Cost Information Network. (In Chinese). Available online: http:/ / www.cecm.net.cn/ (accessed on 28 November 2021).

42. Chen, Y.L. Research on Evaluation and Time Sequence Optimization Model for the Development of Regional Renewable Energy Power Generation Projects; North China Electric Power University: Beijing, China, 2018. (In Chinese)

43. Srinivas, N.; Kalyanmoy, D. Multi-objective Optimization Using Nondominated Sorting in Genetic Algorithms. IEEE Trans. Evol. Comput. 1994, 2, 221-248.

44. Deb, K.; Agrawal, S.; Pratap, A.; Meyarivan, T. A fast elitist non-dominated sorting genetic algorithm for multi-objective optimization: NSGA-II. Evol. Comput. 2000, 1917, 849-858.

45. National Grid Hubei Electric Power Company. Detailed Rules for Budget Estimate of Power Transmission and Transformation Projects, 2018. (In Chinese). Available online: https:/ / wenku.baidu.com/view/f2ea20bb8beb172ded630b1c59eef8c75ebf956c.html (accessed on 4 December 2021). 